\title{
PENGARUH PENERAPAN SISTEM AKUNTANSI KEUANGAN DESA DAN KUALITAS APARATUR DESA TERHADAP KINERJA KEUANGAN DESA KECAMATAN PULAU RAKYAT KABUPATEN ASAHAN
}

\author{
${ }^{1}$ Nuri Jelita Sinaga,, Syofyan, ${ }^{3}$ Mas`ut. ${ }^{4}$ Abdul Rasyid \\ ${ }_{123^{4}}$ Universitas Islam Sumatera Utara \\ ${ }^{1}$ nur.jelita@gmail.com, ${ }^{2}$ syofyan@uisu.ac.id, ${ }^{3}$ mas'ut@fe.uisu.ac.id, ${ }^{4}$ abdul.rasyid@fe.uisu.ac.id
}

\begin{abstract}
The government accounting system is a systematic series of procedures, operators, equipment, and other elements to realize the accounting function from transaction analysis to financial reporting within government organizations. Quality is defined as the whole of a product, person and process or system that can meet expectations (expectations) or meet the desired satisfaction. Quality human resources are supported by educational backgrounds, often attend education and training and have experience in finance. The performance of village financial management determines whether or not village goals are achieved. Poor financial management performance which is characterized by inconsistent and standardized recording and reporting can make the process of evaluating the use of funds difficult to do. About village financial management implies the importance of applying the principles of transparency, accountability, participatory in the preparation of village finances. Village financial system. In addition to the need for adequate competence and understanding of accounting from each individual, adequate supervision is also needed in managing the village financial system. The management of village finances is still lacking in supervision and lack of tightening of the use of the budget. This study aims to determine the village financial accounting system and the quality of the village apparatus on village financial performance in Pulau Rakyat Subdistrict, Asahan Regency and find out whether the village financial accounting system and the quality of the village apparatus on village financial performance are in accordance with the theory and techniques of the accounting system carried out in this study. by distributing questionnaires.
\end{abstract}

Keywords: Accounting System, Apparatus Quality, Performance.

ABSTRAK : Bentuk moneter rezimmelambangkan deretan sistematik dari jalan, pelaksana, bahan, dan poin bedakepada melaksanakan guna akuntansi mulai uraian perundingantamatataspeliputan finansial di areaformasi daerah. Kualitas di definisikan sebagai keseluruhan dari suatu produk, orang dan proses atau sistem yang dapat memenuhi harapan (ekspestasi) atau memenuhi kepuasan yang diinginkan Sumberdaya insan yang berbobot di dukung atas kerangka nantibimbingan, adakalanyamembayangi bimbingan dan pelatihan dan mempunyai pengalaman dibidang keuangan. Kemampuan pengurus moneter daerah memilihteraih atau tiadanya arah daerah.Kemampuan pengurus moneter yang cacat yang dikualitasisamapencoretan dan peliputan yang tiada selaras dan pantaslazim bolehmencetak metode evaluasipemakaian dana selaku berat dilakukan Tentang pengurus moneter daerah membatasi bergunanya pelaksanaandasar transparansi, akuntabilitas, partisipatif intens penataan keuangan daerah. Sistem moneter daerah.Selaian di perlukannya kompetensi dan pemahaman akuntansi yang memadai dari setiap individu diperlukan juga pengawasan yang cukup dalam pengelolaan sistem keuangan desa.Tata moneter daerah tengah minim penjagaan dan rendahnya penyekatan terhadap pemakaian perkiraan. Pengkajian berikutberniat kepada mendapatmetode akuntansimoneter daerah dan bobot aparatur daerah terhadap kemampuan pengurus moneter daerah Kecamatan Pulau Rakyat Kabupaten Asahan dan menangkap apakah struktur akuntansi keuangan daerah dankemampuan pengurus daerah terhadap kinerjamoneter desa telah sinkron atas aturan dan teknik bentuk akuntansi yakni dilakukan dalam penelitian berikut atas penyebaran kusioner.

Kata Kunci : Sistem Akuntansi, Kualitas Aparatur, Kinerja.

\section{Pendahuluan}

Keadaan Aparatur desa sekarang kemampuannya masih rendah, terutama dalam pengelolaan keuangan daerah. Pertanggung jawaban aparatur desa dalam memecahkan kesulitan yang timbul di desa dapat melungsur kualitas dari suatu sistem akuntansi yang ada di desa tersebut.Pengenalan pada pencatatan,
Penjabaran dalam setiap pencatatan disistem akuntansi keuangan memapah transisis yang jelas terhadap akuntansi moneter daerah.Pengelompokan yakni setuju pula pasti menaikkan bobot daerah.Problemamengenai akuntabilitas untuk mengelola keuangan desa bisa diakses melaluimetode akuntansi terhadap daerah, nyata yang terus di terapkan per 
bagiannya, keapsahanpenerangan yang dipunyai dengan wakil pengurus daerah bisa membuat pergantianbeserta pilihan buatan yang diatur meraka beserta yang di atur kepadainsan yang berbeda.Di era ini banyak masyarakat yang mempersoalkan tentang kejelasan anggaran, yang mana alat dan juga aparatur desa nya minim dilatih bersama bidang pengurusdaerah.dengan kinerja yang dapat diandalkan dalam pengelolaan akuntansi keuangan yang diterapkan kepada aparatur daerahmembuatdaerah juga pengelolaan akuntansinya menuju aspek ketelitian sebagaipengawas keuangan nya, ataupun bisadiungkapkan masyarakatmenjadi percaya. Penataannilai instansi desa diterapkan serasi atas prinsip-prinsip yang tersedia. Agenda pengeluaran desa mengacu atas prinsip irit, sederhana, efektif, yang singkron dengan peraturan perundang-undangan. Pencatatan belanja, pendapatan dan pembiayaan dijalankan secara transparanbagitokoh yang berwewenang didalam organisasi keuangan desa.

Mengenai itu adakalanya setiap pengurus finansial wajib mempunyai pemahaman yang layakberkenaan dengan keterangan finansial yang mana keterangan keuangan yaitu ditayangkan bisa diberi sebagai lumrah leluasa untuk salah terapkan yaitu material sehingga tidak salah arah pembaca dan pengguna laporan. Tidak ada penalaraninformasifinansial yang baik menyebabkan informasi kuangan yaitu dibagikan adanya kecerobohanpemahaman dalam penyajian angka, tidak cocokdengan pemberitahuan dan tidak sesuaidengan yang disampaikan olehnya berakibat fatal oleh pengguna laporan itu sendiri.

\section{Landasan Teori}

\subsection{Pengertian Sistem.}

Selakulorek kuat metode merupakan suatu fungsi gabunganbagian atauanasir juga silih integral, bagian juga terorganisir juga hidup saatmelaksanakan sebuah arahyang diinginkan. Kata lain menurut (Hutahean, 2015) mendepankan bahwa "sistem adalah suatu jaringan kerja dari prosedur-prosedur yang saling berhubungan, berkumpul bersama-sama untuk melakukan kegiatan atau untuk melakukan sasaran yang tertentu. Berdasarkan pendapat dari para ahli diatas, dapat disimpulkan bahwa sistem merupakan suatu kumpulan komponen dari subsistem yang saling bekerja sama dari prosedur-prosedur yang saling berhubungan untuk menghasilkan output dalam mencapai tujuan tertentu.

\subsection{Unsur-unsur Sistem Akuntansi.}

Menurut(Mulyadi, 2013:3), lima unsur pokok dalam sistem akuntansi yaitu: (1) Formulir (2) Jurnal (3)Buku besa (4) Buku pembesar (5) Laporan.

\subsection{Pengertian Kualitas Aparatur.}

Kemenangan pemerintah pemerintah desa termasuk aparat pemerintah desa dalam pelaksanaan tanggung jawabnya yang esensinya adalah sebagai penyelenggaraan fungsi pelayanan. Salah satu sorotan yang menghambat kinerja pelayanan publik di daerah pedesaan disebabkan karena kurangnya pemahaman dan kesadaran aparat pemerintah desa terhadap bidang pelayanan tersebutanatara lain rendah ya kualitas aparat sehingga mempengaruhi sistem pelayanan yang maksimal.

Sistem pelayanan yang maksimal dapat terukur dan teraplikasikan dengan baik apabila didukung dengan perangkat sebagai pelaksana yang mampu memahami tugas-tugasnya (Negara et al., 2018)

\subsection{Pengertian Kinerja Keuangan.}

Kinerja finansial pemerintah daerah yaitu suatu kemampuanyang dipunya daerah dalam menggali, mengelola dan memanfaatkan potensi keuangan asli desa dalam mendukung jalannya sistem pemerintahan, pelayanan masyarakat, dan pembangunan desanya agar tidak memiliki kebergantungan sepenuhnya kepada pemerintah pusat serta mempunyai kebebasan penuh menggunakan dana bagi kepentingan masyarakat desa untuk batas-batasan yang ditetapkan peraturan perundang-undangan yang berlaku.) (Bastian, 2006) menjelaskan tujuan pengukuran kinerja keuangan yakni laporan operasi kegiatan pemerintah guna menilai kinerja kinerja keuangan organisasi terkait efisiensi dan efektifitas juga mengawasi biaya aktual jika dibanding biaya dalam rencana anggaran. Dalam meningkatkan akuntabilitas serta kualitas pengambilan keputusan digunakan alat manajemen berupa pengukuran kinerja (wenny, 2012).

\subsection{Tujuan pokok sistem akuntansi pemerintah.}

Halim \& Kusufi,( 2012)tujuan pokok yang terkait di dalam sistem akuntansi pemerintah adalah (1) Pertanggung jawaban (2) Manajerial (3) Pengawasan.

\section{Metode Penelitian}

\subsection{Jenis dan Sumber Data.}

Penelitian ini menerapkanData yangdipakai di penelitian ini yakni data primer, yaitudormasi yangdidapat secara instan dari sumber awal yaitu dari peninjauan ke objek penelitian atau responden.

\subsection{Teknik Pengumpulan Data.}

Di penelitian ini metode yang dipakai untuk mendapatkan informasi dari responden yakni berbentuk kuesioner.Jenis kuesioner yang penulis 
pakai adalah kuesioner tertutp, yakni kuesioner yang telah disediakan jawabannya.

\subsection{Teknik Analisis Data.}

Teknik analisis data yang dipakai di penelitian ini ialah teknik analisis statistik deskriptif yang menggunakan software atau aplikasi SPSS.Statistik deskriptif mengacu pada beberapa 4.1. Analisis Statistik Deskriptif. hal, antara lain rata-rata (mean), standar deviasi, nilai maksimum, nilai minimum, dan jumlah data, frekuensi data, dan kecenderungan data.

\section{Hasil Penelitian}

Pengaruh Penerapan Sistem Keuangan Dan Kualitas Aparatur Desa Terhadap Kinerja Keuangan Desa.

Tabel 1. Hasil Analisis Statistik Deskriptif' Descriptive Statistics"

\begin{tabular}{|l|r|r|r|r|r|}
\hline & \multicolumn{1}{|c|}{ N } & Minimum & Maximum & Mean & Std. Deviation \\
\hline X1 & 36 & 44 & 64 & 53,72 & 4,972 \\
X2 & 36 & 21 & 32 & 28,25 & 3,148 \\
Y & 36 & 38 & 53 & 47,42 & 4,656 \\
Valid N & 36 & & & & \\
(listwise) & & & & & \\
\hline
\end{tabular}

Sumber : Data diolah dengan SPSS, 2021

Berdasarkah hasil analisis pada data output di atas, dapat dijelaskan bahwa $\mathrm{N}$ atau jumlahresponden sebanyak 36 orang. Pada data kuisioner untuk variabel independen, peneliti memasukkan 15 pertanyaan untuk variabel $X_{1}$ (Penerapan Standar Akuntansi), 8 pertanyaan untuk variabel $\mathrm{X}_{2}$ (Kualitas Aparatur Desa), dan13 pertanyaan untuk variabel $Y$ (Kinerja Keuangan Desa). Dari hasil pada data output di atas, maka juga akan diketahui penggambaran pada data tersebut, yaitu sebagai berikut :

1) Variabel $X_{1}$ (Penerapan Sistem Akuntansi) mempunyai nilai minimum sebesar44, nilai maksimum sebesar 64, nilai rata - rata (mean) sebesar 53,72, dengan standar deviasi sebesar 4,972 .

2) Variabel $X_{2}$ (Kualitas Aparatur Desa) mempunyai nilai minimum sebesar 21 , nilai maksimum sebesar 32, nilai rata - rata (mean) sebesar 28,25, dengan standar deviasi sebesar 3,148 .

3) Variabel Y (Kinerja Keuangan Desa) mempunyai nilai minimum sebesar 38 , nilai maksimum sebesar 53, nilai rata - rata (mean) sebesar 47,42, dengan standar deviasi sebesar 4,656 .

\subsection{Uji Validitas Variabel $X_{1}$ (Penerapan Sistem Akuntansi)}

Tabel 2. Hasil Uji Validitas Variabel $\mathrm{X}_{1}$

\begin{tabular}{|l|c|c|c|c|c|}
\hline \multicolumn{1}{|c|}{ Butir Pertanyaan } & Sig. & $\mathbf{r}_{\text {hitung }}$ & $\mathbf{r}_{\text {tabel }}$ & Keterangan \\
\hline Item 1, Pearson Correlation & 0,000 & 0,592 & 0,329 & Valid \\
\hline Item 2, Pearson Correlation & 0,004 & 0,466 & 0,329 & Valid \\
\hline Item 3, Pearson Correlation & 0,000 & 0,700 & 0,329 & Valid \\
\hline Item 4, Pearson Correlation & 0,000 & 0,647 & 0,329 & Valid \\
\hline Item 5, Pearson Correlation & 0,000 & 0,766 & 0,329 & Valid \\
\hline Item 6, Pearson Correlation & 0,000 & 0,617 & 0,329 & Valid \\
\hline Item 7, Pearson Correlation & 0,000 & 0,567 & 0,329 & Valid \\
\hline Item 8, Pearson Correlation & 0,002 & 0,489 & 0,329 & Valid \\
\hline Item 9, Pearson Correlation & 0,010 & 0,425 & 0,329 & Valid \\
\hline Item 10, Pearson Correlation & 0,021 & 0,384 & 0,329 & Valid \\
\hline Item 11, Pearson Correlation & 0,000 & 0,620 & 0,329 & Valid \\
\hline Item 12, Pearson Correlation & 0,000 & 0,670 & 0,329 & Valid \\
\hline Item 13, Pearson Correlation & 0,009 & 0,431 & 0,329 & Valid \\
\hline Item 14, Pearson Correlation & 0,006 & 0,451 & 0,329 & Valid \\
\hline Item 15, Pearson Correlation & 0,000 & 0,621 & 0,329 & Valid \\
\hline
\end{tabular}

Berdasarkan hasil pada data output di atas, menunjukkan bahwa butir pertanyaan pada penelitian ini, dapat dinyatakan valid secara keseluruhan. Hal ini berarti keseluruhan dari butir pertanyaan tersebut mampu untuk mengungkapkan sesuatu yang akan diukur.

4.3. Uji Validitas Variabel $\mathbf{X}_{2}$ (Kualitas Aparatur Desa) 
Tabel .3. Hasil Uji Validitas Variabel $\mathrm{X}_{2}$

\begin{tabular}{|l|c|c|c|c|c|}
\hline \multicolumn{2}{|c|}{ Butir Pertanyaan } & Sig. & $\mathbf{r}_{\text {hitung }}$ & $\mathbf{r}_{\text {tabel }}$ & Keterangan \\
\hline Item 1, Pearson Correlation & 0,000 & 0,702 & 0,329 & Valid \\
\hline Item 2, Pearson Correlation & 0,000 & 0,731 & 0,329 & Valid \\
\hline Item 3, Pearson Correlation & 0,000 & 0,740 & 0,329 & Valid \\
\hline Item 4, Pearson Correlation & 0,000 & 0,761 & 0,329 & Valid \\
\hline Item 5, Pearson Correlation & 0,000 & 0,734 & 0,329 & Valid \\
\hline Item 6, Pearson Correlation & 0,000 & 0,794 & 0,329 & Valid \\
\hline Item 7, Pearson Correlation & 0,002 & 0,493 & 0,329 & Valid \\
\hline Item 8, Pearson Correlation & 0,000 & 0,559 & 0,329 & Valid \\
\hline
\end{tabular}

Berdasarkan hasil pada data output di atas, menunjukkan bahwa butir pertanyaan pada penelitian ini, dapat dinyatakan valid secara

keseluruhan. Hal ini berarti keseluruhan dari butir pertanyaan tersebut mampu untuk mengungkapkan sesuatu yang akan diukur.

\subsection{Uji Validitas Variabel Y (Kinerja Keuangan Desa)}

Tabel 4. Hasil Uji Validitas Variabel Y

\begin{tabular}{|l|c|c|c|c|}
\hline \multicolumn{1}{|c|}{ Butir Pertanyaan } & Sig. & $\mathbf{r}_{\text {hitung }}$ & $\mathbf{r}_{\text {tabel }}$ & Keterangan \\
\hline Item 1, Pearson Correlation & 0,001 & 0,513 & 0,329 & Valid \\
\hline Item 2, Pearson Correlation & 0,000 & 0,810 & 0,329 & Valid \\
\hline Item 3, Pearson Correlation & 0,000 & 0,796 & 0,329 & Valid \\
\hline Item 4, Pearson Correlation & 0,000 & 0,605 & 0,329 & Valid \\
\hline Item 5, Pearson Correlation & 0,089 & 0,287 & 0,329 & Tidak Valid \\
\hline Item 6, Pearson Correlation & 0,085 & 0,291 & 0,329 & Tidak Valid \\
\hline Item 7, Pearson Correlation & 0,127 & 0,259 & 0,329 & Tidak Valid \\
\hline Item 8, Pearson Correlation & 0,025 & 0,374 & 0,329 & Valid \\
\hline Item 9, Pearson Correlation & 0,017 & 0,396 & 0,329 & Valid \\
\hline Item 10, Pearson Correlation & 0,005 & 0,456 & 0,329 & Valid \\
\hline Item 11, Pearson Correlation & 0,000 & 0,750 & 0,329 & Valid \\
\hline Item 12, Pearson Correlation & 0,000 & 0,768 & 0,329 & Valid \\
\hline Item 13, Pearson Correlation & 0,000 & 0,788 & 0,329 & Valid \\
\hline
\end{tabular}

Berdasarkan hasil pada data output di atas, menunjukkan bahwa pertanyaan nomor 5 ,nomor 6, dan nomor 7 dinyatakan tidak valid. Sedangkan pertanyaan lainnya pada kuisioner, dinyatakan telah valid.

\subsection{Uji Reliabilitas Variabel $X_{1}$ (Penerapan Sistem Akuntansi)}

Tabel 5. Hasil Uji Reliabilitas Variabel $X_{1}$ Reliability Statistics

\begin{tabular}{|r|r|}
\hline $\begin{array}{c}\text { Cronbach's } \\
\text { Alpha }\end{array}$ & N of Items \\
\hline, 744 & 16 \\
\hline
\end{tabular}

Berdasarkan tabel di atas, menunjukkan bahwa nilai pada cronbach's alpha sebesar 0,744 $>$ 0,60. Maka dapat disimpulkan bahwa, kuisioner pada variabel $\mathrm{X}_{1}$ (Penerapan Sistem Akuntansi) dinyatakan reliabel atau konsisten.

4.6. Uji Reliabilitas Variabel $X_{2}$ (Kualitas Aparatur Desa)

Tabel 6. Hasil Uji Reliabilitas Variabel $\mathrm{X}_{2}$ Reliability Statistics

\begin{tabular}{|c|c|}
\hline $\begin{array}{c}\text { Cronbach's } \\
\text { Alpha }\end{array}$ & N of Items \\
\hline
\end{tabular}

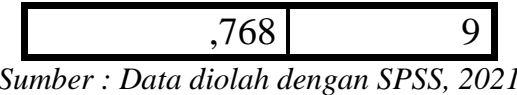

Berdasarkan tabel di atas, menunjukkan bahwa nilai pada cronbach's alpha sebesar 0,768> 0,60. Maka dapat disimpulkan bahwa, kuisioner pada variabel $\mathrm{X}_{2}$ (Kualitas Aparatur Desa) dinyatakan reliabel atau konsisten.

\subsection{Uji Reliabilitas Variabel Y (Kinerja Keuangan Desa)}

Tabel 7. Hasil Uji Reliabilitas Variabel Y Reliability Statistics

\begin{tabular}{|c|r|}
\hline $\begin{array}{c}\text { Cronbach's } \\
\text { Alpha }\end{array}$ & N of Items \\
\hline S41 & 14 \\
\hline
\end{tabular}

Dilihat dari tabel di atas, menunjukkan bahwa nilai pada cronbach's alpha sebesar 0,741 >0,60. Maka bisa dirangkum bahwa, kuisioner pada variabel Y (Kinerja Keuangan Desa) dinyatakan reliabel atau konsisten.

\section{Kesimpulan}

Bersumber buatan pemeriksaan atas memakai analisis regresi linier berganda dan pengujian 
hipotesis, alkasih memperoleh ditarik suatu kesimpulan, yaitu sebagai berikut :

1) Penerapan Sistem Akuntansi berpengaruh negatif dan tidak signifikan secara parsial terhadap Kinerja Keuangan Desa.

2) Kualitas Aparatur Desa berpengaruh positif dan signifikan secara parsial terhadap Kinerja Keuangan Desa.

3) Penerapan Sistem Akuntansi dan Kualitas Aparatur Desa berpengaruh positif dan signifikan secara simultan terhadap Kinerja moneter Daerah.

\section{DAFTAR PUSTAKA}

Anwar, Misbahul, Bambang, J. 2010. Kontribusu dan Peran Pengelolaan Keuangan Daerah
Untuk Mewujudkan Anggaran Pendapatan Belanja Daerah Yang Transparan dan Akuntabel.Universitas Muhammadiyah Yogyakarta.

Anwar Sanusi. 2014 Metodologi Penelitian Bisnis.

Hamidi. 2005. Metode Penelitian Kualitatif. Malang: UMM Press.

Irma, Ade. 2014 Akuntabilitas Pengelolaan Keuangan Daerah. Kabupaten Sigi.

Ismail Muhammad, Widagdo Ari, Widodo Agus. 2016 Sistem Akuntansi Pengelolaan Keuangan Daerah. Desa Kismoyoso dan Desa Giriroto 